\title{
Segmented Labor Markets and the Distributive Cycle: A Roadmap towards Inclusive Growth
}

\author{
Matthieu Charpe, ${ }^{1}$ Peter Flaschel, ${ }^{2}$ Florian Hartmann, ${ }^{3}$ and Christopher Malikane ${ }^{4}$ \\ ${ }^{1}$ International Labour Organization, 1211 Geneva, Switzerland \\ ${ }^{2}$ Bielefeld University, 33615 Bielefeld, Germany \\ ${ }^{3}$ University of Osnabrück, 49069 Osnabrück, Germany \\ ${ }^{4}$ University of the Witwatersrand, Johannesburg 2050, South Africa
}

Correspondence should be addressed to Florian Hartmann; florian.hartmann@uni-osnabrueck.de

Received 9 January 2014; Accepted 7 April 2014; Published 30 April 2014

Academic Editor: David E. Giles

Copyright (C) 2014 Matthieu Charpe et al. This is an open access article distributed under the Creative Commons Attribution License, which permits unrestricted use, distribution, and reproduction in any medium, provided the original work is properly cited.

\begin{abstract}
The paper builds on the Goodwin (1967) model which describes the distributive cycle of capitalist economies whereby mass unemployment is generated periodically through the conflict about income distribution between capital and labor. We add to this model a segmented labor market structure with fluid, latent, and stagnant components. The model exhibits a unique balanced growth path which depends on the speeds with which workers are pushed into or out of the labor market segments. We investigate the stability properties of this growth path with segmented labor markets and find that, though there is a stabilizing inflation barrier term in the wage Phillips curve, the interaction with the latent and stagnant portions of the labor market generates potentially (slowly) destabilizing forces if policy measures are absent that regulate these labor markets. We then introduce an activating labor market policy, where government in addition acts as employer of last resort thereby eliminating the stagnant portion of the labor market, whilst erecting benefit systems that partially sustain the incomes of workers that have to leave the floating/latent labor market of the private sector of the economy. We show that such policies guarantee the macrostability of the economy's balanced growth path.
\end{abstract}

\section{Introduction}

1.1. The Theory of Segmented Labor Markets and the Case of Germany as a Contemporaneous Example. In this paper we reconsider the trichotomy of floating, latent, and stagnant segments of the labor market in the framework of the Goodwin [1] model of the distributive cycle and discuss this concept of segmented labor markets both from the theoretical and the empirical perspectives. The significance and relevance of this trichotomy can be easily observed with regard to the situation of labor markets in both advanced and developing countries. Marx introduced this theory of specifically segmented labor markets in conjunction with his discussion of the general law of capitalist accumulation in Capital, Volume I. Reconsidering the Marxian trichotomy of floating (fluid), latent, and stagnant segments of the labor market, where the last segment-the stagnant onecan also be described as a dead segment, we can easily discover similarities on the level of well-being (not in absolute income of course) to the situation of the employees in the German economy of the 21st century. We have normal occupations, the floating segment, atypical employment in the low income sector (part-time workers, temporary work organized by special leasing firms and low paid), so-called minijobs, in the latent segment, and unemployed persons receiving unemployment benefits (for one year, elderly people for 18-24 months), and long-term unemployed persons, with only marginal chances of a return to proper work, in the dead segment of the labor market.

Germany had a regulation for unemployed persons until 2005 which consisted of two forms of unemployment support, a maximum of two years of unemployment benefits, 
and thereafter "Sozialhilfe" (social help) with a smaller sum of money. In general, the length of payment and some other decisions were dependent on the length of working time before becoming unemployed and thus on the amount of payment into the unemployment insurance which wasand is-obligatory in Germany (see Blien et al. [2] for an overview of the situation of unemployed persons and German regulations before the so-called "Hartz reforms").

In 2005, a radical labor market "reform" took place against which protests have never stopped. It is named "Hartz IV" because one of the main persons involved in the creation was Peter Hartz, a former German CEO, among others at the Volkswagen enterprise. A reason for the new regulation was the high increase of unemployed persons at the end of the 20th and beginning of the 21st centuries so that a commission was founded, the Hartz Commission, which intended to reduce the number of more than four million unemployed persons to less than half of it within four years, which however never happened. The new regulations have reduced the payment of unemployment benefits to one year and put together "Sozialhilfe" (social help) and a new unemployment benefit system II, better known in Germany under the name Hartz IV. The number IV can be explained by the following development from 2002 on (see Tompson [3], 229ff.):

(i) Hartz I (implemented in 2003) made reforms of the restrictive legislation on temporary work and work leasing, both of which were eased. Stricter rules with regard to registering as unemployed and accepting offered work were made;

(ii) Hartz II (also implemented in 2003) has renewed the possibilities of founding a one-person business (IchAG) and made a reform of the minijobs (income up to 400 Euro) which do only demand (small) social securities payment from the employer, but not from the employee;

(iii) Hartz III (implemented in 2004) includes a reorganisation of the employment agency and special rules of cutting benefits if an offered work is not accepted without understandable reasons;

(iv) Hartz IV (implemented in 2005) has merged Sozialhilfe (social help) and unemployment benefit with unemployment benefit II which is at present fixed on 364 Euro per month (plus payment of rents, etc.). For children there exist further standard rates.

While the-in 2004 renewed-Federal Institute for Employment has to deal with unemployed persons and try to find jobs for them and to organize the Hartz IV-payment, the underlying laws are to be found in the German Social Security Codes II and III which regulate the work of the Federal Institute for Employment. Both codes have been updated in recent years. While the main topics in Social Security Code II deal with basic social care as well as employment promotion, the dominant aspects in Social Security Code III refer to jobcreating measures and job training. Hartz IV recipients are mainly part of Security Code II, while unemployed persons who receive unemployment benefits for one year (about 60\% of their former income) are dealt with in Security Code
III though some tasks are mixed. Persons who earn only little in a job can receive an additional support within the Hartz IV regulations. A basic principle in both codes is the orientation towards workfare in contrast to welfare, which means that unemployed persons are supposed to engage themselves in skill enhancement and intensive job finding (Federal Statistical Office [4]).

In 2009, there were 43 million persons in the active part of the German labor force, but nearly five million persons had only a so-called minijob (Eurofound [5]). Since the 1990s the number of low wage jobs has significantly increased by up to $20 \%$ of all employees. (See Bosch and Kalina ([6], 19ff.) for the development in the last twenty years.) Additionally, the German government refused a general minimum wage for years. But this has changed since the federal elections in late 2013. The introduction of a minimum wage is currently on the way. Solow ([7], 12ff.) discusses several possible reasons for the German downward development in labor market regulations, among which the growth of the service sector (in contrast to the manufacturing sector), gradual weakening of union power, intensified competition through incoming workers, for example, from Eastern Europe, and relics of the Bismarckian organisation of the German welfare state (especially the "male breadwinner household") are underlined as possible negative influences. $\mathrm{He}$-as well as Bosch and Weinkopf [8] and Bosch and Kalina [6] — argues that the introduction of minimum wages might be a first step away from this downward development.

In 2010, there were 3244000 unemployed persons, following the information of the Federal Institute for Employment, which is a significant fall compared to 2009. Altogether, around 6 million employable persons received in 2010 benefits due to the Social Security Codes II and III, which means a reduction of $2 \%$ with regard to the preceding year, mainly with regard to those who received unemployment benefits. There were on the other hand one and a half million persons involved in a measure of labor market policy, mainly a form of skill training, which was nearly $15 \%$ less than in 2009 , which means reduced support in finding a new job.

The data of unemployed persons shows that more than $20 \%$ of the Hartz IV receivers are long-term unemployed meaning for more than 24 months (Bundesagentur für Arbeit, 2010), but many Hartz IV receivers are in this system for more than five years and more than 10 years even. This problem is related to the question of sufficient qualifications which are often missing. Therefore, the so-called Hartz IV people are often linked to the so-called problem groups, which include migrants without any professional or even educational qualifications, single parent households, unskilled persons in general, and early school leavers.

While the data from the Federal Statistical Office seem to suggest not only lots of different supports for unemployed persons, but also a decreasing number of unemployed persons (of both types), the situation of these parts of the society is far from being satisfactory (Bundesagentur für Arbeit [9]).

The situation of Hartz IV receivers is not only close to poverty, a fact which is especially difficult for children and juveniles, but it also contains many degrading situations since persons who apply for Hartz IV not only have to reveal the 
details of their financial situation (savings, properties, etc.) and their living conditions (family, friends, etc.), but also are forced to change their living place when they have too many rooms or pay a high rent (which will be overtaken by the agency). Furthermore they have to apply for all extra expenses, including clothing, birthday presents, and traveling to a sick relative.

Another degrading aspect is the often low support in finding a new job or even getting new qualifications which gives a feeling of being no longer part of the workforce. Furthermore, the public opinion on idle workforce members who are viewed as refusing work can be, and is, also degrading. It has also to be taken into consideration that many long-term unemployed persons who live from Hartz IV will get into a difficult situation when they are old because their retirement pension can be very low so that they will depend on the paid basic social help for aged persons.

Therefore, it is correct to compare Hartz IV with the stagnant (dead) segment of Marx's classification as described above. Of course, their situation is not comparable to the situation of the dead segment on the labor market at his times, but in a cross-sectional comparison they are nevertheless in a comparable position concerning life perspectives, neighborhood problems, tendencies to drug consumption, and inclination towards violence.

Moreover, there are certainly many difficult atypical working conditions in Germany that can be related to the Marxian latent segment though these workers have a chance to move up into the floating segment like skilled and welltrained unemployed persons who may find a new job after some months. On the other hand, there are many persons in this segment who can also easily drop into the stagnant segment when, for example, part-time occupied workers lose their job, or temporary work organized by special leasing firms is so low paid that the comparison with regular workers is discriminating. These types of workers are indeed also supported through the Hartz IV program to a significant degree (around 3/4 of the Hartz IV receivers).

Unemployment is, of course, the root of all these problems. In this paper we will therefore-among other questions-also deal with proposed solutions to solve this problem such as basic income guarantee (BIG) (the Hartz IV contributions of the state currently amount to roughly 500 Euro per head) or an employer of last resort (ELR). The importance of such programs cannot be underestimated, since the increase in child poverty that is accompanying mass unemployment is indeed of the type of a ticking time bomb (in Germany social help supplied to children increased from 130000 children in 1965 to 1.7 million children in 2010). To have approximately $10 \%$ of workers in the new classification system "Hartz IV families" who are by and large chronically unemployed with no hope for improvement of their lot represents a situation in a democracy that can only be considered as fatal. This paper will provide against such a background a model of Marx's segmented labor market analysis and a reform proposal that tries to cure such a situation.
1.2. Modeling Strategy. Goodwin's [1] Marxian growth cycle model is one of the truly baseline models of macroeconomic theory, comparable to the orthodox Solow [10] model in its simplicity, but totally different in its implications from the latter type of growth theory. (See Flaschel [11] for a detailed study of this type of approach.) This has indeed also been acknowledged by Solow himself (see Solow [12]) and has led to numerous publications on modifications and extensions of this approach to a distributive cycle.

Barbosa-Filho and Taylor [13] have characterized this cycle mechanism; see also Taylor ([14], ch. 9) in this regard. Recently, in 2006, there has been a special issue in the Journal Structural Change and Economic Dynamics [15] on Goodwin's legacy and its continuation as well as an edited volume on this subject; see Flaschel and Landesmann [16]. There has also been recent empirical work on this distributive cycle by Harvie [17], Veneziani and Mohun [18, 19], Franke et al. [20], Fiorio et al. [21], and others. This indicates that the model of the reserve army mechanism designed by Goodwin $[1,22]$ on the basis of Marx's analysis of this mechanism is still attracting numerous studies of its further development and its empirical evaluation.

The paper shows that Goodwin's model, which is characterized by the unrestricted operation of the "law of capitalist accumulation," can be reformulated in such a way as to produce socioeconomic outcomes that are socially and politically acceptable. We should however mention that, in our formulation of reformed capitalism, the role of changes in the composition of capital remains to be explored. In his detailed exposition of the operation of capitalist accumulation, Marx places great emphasis on the rise in the organic composition of capital as a principal force behind the increase in structural unemployment. We do not pursue this matter in this paper. Our main focus is to integrate the three segments of the labor market under the assumption of a given capital intensity (constant labor productivity) and to show, on this basis, that active labor market policy can generate an outcome that eliminates the stagnant portion of unemployment.

From this perspective, this paper reconsiders the growth cycle of Goodwin [1] to incorporate the various forms of unemployment pointed out by Marx [23]: the floating, latent, and stagnant segments of the labor market. In Goodwin's model, only the floating type of unemployment was considered. We reformulate Goodwin's model by postulating an interaction between the three labor market segments. We then investigate its steady state positions and their stability in this extended framework. We then show that, in the presence of a benefit system that is undertaken by government as "employer of last resort," the stagnant segment of the labor market can be assumed as eliminated, which improves the stability of the economy. (To our knowledge, the first study of an unemployment benefit system in the context of the Goodwin growth cycle model was provided by Glombowski and Krüger [24].) The paper thus shows that Goodwin's model, which is in a way characterized by the unrestricted operation of the "law of capitalist accumulation," can be reformulated in such a way as to produce socioeconomic outcomes that are socially and politically acceptable. 
The rest of the paper is structured as follows. Section 2 adds to the Goodwin model a segmented labor market structure, in which the different types of unemployment interact on the basis of rates of employment and unemployment. Section 3 provides a steady state analysis of the model and shows that the steady state rates of employment in the latent and stagnant segments depend on the speeds with which workers are pushed into or out of these segments. It also investigates the stability properties of the extended model, both from the theoretical and the numerical perspective. We find that adding the latent and stagnant portions of the labor market in this model generates potentially destabilizing forces, though there is a stabilizing inflation barrier term in our Phillips curve formulation. Section 4 introduces an active labor market policy where government acts as employer of last resort, thereby eliminating the stagnant portion of the labor market, whilst erecting a benefit system that sustains the incomes of workers that leave the floating labor market into the latent one. We show that this policy guarantees the macrostability of the economy's growth path. Section 5 briefly considers the historical origins of social legislation in Germany and presents possible future policies that intend to replace the Hartz IV system in a stepwise fashion by civic work. Section 6 concludes.

\section{The Model: Segmented Labor and the Distributive Cycle}

The model of the distributive cycle of Flaschel and Greiner [25] can serve as a major reference point to the approach put forth in this paper. Their model describes by its construction a viable situation for a capitalist economy. In that model, it is shown that the introduction of a benefit system and minimum and maximum real wage rules obtained through a social pact between labor and capital significantly improves the economic performance of Goodwin's [1] reserve army economy. However, there is one serious neglect in such a scenario. Mass unemployment occurs without any social consequences for the household structure of the working class. In Marx's description of the reserve army mechanism this is taken note of and it is even claimed there that the distributive cycle necessarily implies a hierarchy of three segments in the labor market, the fluid (note that the terms fluid and floating will be used synonymously throughout the paper), the latent, and the stagnant one (the terms stagnant and dead are interchangeable with respect to the lowest segment of the labor market). The existence of such hierarchy is unavoidable under an unrestricted evolution of the capitalist mode of production. In this paper, as distinct from Flaschel and Greiner [25], we provide a model in which these labor market and unemployment hierarchies are present and interacting.

Before starting the discussion of the model let us briefly state that Goodwin-type models are pure supply side models where Says's law holds since all wages are consumed and all profits are invested. (This fact might be no serious restriction for the policy conclusions we will derive from the model. Though demand issues are for sure of importance as well, any arguments made in favor of the wage side would only be strengthened by the incorporation of aggregate demand aspects. Thus, we consider to use a supply side approach to be ideally adequate to challenge orthodox supply-side oriented models' policy implications.) The Goodwin-type models also assume free hiring and firing, since no delays concerning employment adjustment processes are normally present in them. We moreover exclude government activities from consideration and are thus assuming with respect to the unemployed or even those members of the workforce in the stagnant ("dead") segment of the labor market that they are supported by other family members, by the church, by casual work, and from beggary. All these flows between worker households are not modeled explicitly, but only represented through the total wage payment to workers of type 1 or 2 . For interpretational simplicity we consider workers of type 1 as living in the town centers, type 2 as living in the outskirts of town, and the ones of the dead segment as living in the slums.

We consider the Marxian growth cycle model as it was formulated by Goodwin [1], without any consideration of social security yet, but add a consideration of the evolution of latent and stagnant portions of the labor markets. The growth cycle dynamics for the floating labor market can then be formulated (if the other segments of the labor market are still ignored):

$$
\begin{array}{ll}
\widehat{\omega}=\beta_{w}\left(\frac{\bar{y} / \bar{z}}{l^{s}}-\bar{e}\right), & l^{s}=\frac{L^{s}}{K}, \\
\widehat{l}^{s}=n-\bar{y}\left(1-\frac{\omega}{\bar{z}}\right), & \omega=\frac{w}{p},
\end{array}
$$

where $\bar{z}$ is a constant output-labor ratio, $\bar{y}$ a constant output capital ratio, $\omega$ the real wage, $\beta_{w}$ the adjustment speed of the real wage in reaction to the state of the labor market, $\bar{e}$ the steady state employment rate, $L^{s}$ the labor supply, $n$ the growth rate of the labor force, $w$ the nominal wage, and $p$ the price level. Equation (1) says that real wage growth is a function of the deviation of the employment rate from its steady state rate. Equation (2) is an accounting identity describing the growth rate of the labour-capital ratio. Adding the other two segments of the labor market we assume now for the floating part of it (indexed by 1) law of motion for their real wage:

$$
\begin{gathered}
\widehat{\omega}_{1}=\beta_{w e_{1}}\left(\frac{\bar{y} / \bar{z}_{1}}{l_{1}^{s}}-\bar{e}_{1}\right)+\beta_{w e_{2}} e_{2}-\beta_{w d} \frac{D}{L^{s}}+\beta_{w \omega_{1}}\left(\omega_{1}^{o}-\omega_{1}\right), \\
\widehat{l}^{s}=n-\bar{y}\left(1-\frac{\omega_{1}}{\bar{z}_{1}}-\frac{\bar{\omega}_{2}}{\bar{z}_{2}}\right), \quad \frac{\omega_{1}}{\bar{z}_{1}}+\frac{\bar{\omega}_{2}}{\bar{z}}<1 .
\end{gathered}
$$

The real wage Phillips curve in the first labor market remains based on demand pressure term in the first labor market $\left(\left(\bar{y} / \bar{z}_{1}\right) / l_{1}^{s}\right)-\bar{e}_{1}$ and is now augmented by the positive influence of the second labor market through an increasing rate of employment $e_{2}=\left(\left(\bar{y} / \bar{z}_{2}\right) / l_{2}^{s}\right), l_{2}^{s}=L_{2}^{s} / K$ in the atypical (second) labor market and by a negative influence from the third (stagnant) segment of the labor market where there is no employment at all. The extent of this stagnant 
segment is measured by $D / L^{s}=d / l^{s}$ and is related to what Marx's considers as pauperism in chapter 25 , Section 4 . The last term is an error-correction term for the real wage and can be viewed as a way to capture the influence of the rate of profit on the steady state real wage. The law of motion for labor intensity is the same as before but now refers to the whole of labor supply per unit of capital. This is driven by the rate of profit, where the given real wage per unit of capital has now to be deducted. We assume in this paper that the real wage in the latent segment of the labor market is a given subsistence wage, while there are no wages paid at all in the sphere of pauperism. Note that the given magnitudes $\bar{z}_{1}, \bar{z}_{2}$ of output per unit of employed labor have now to be interpreted in inverted form as employment coefficients since they are used here to calculate employment on the two active labor markets on the basis of a given output-capital ratio $\bar{y}$.

Note also that we have, by definition, the identity $L^{s}=$ $L_{1}^{s}+L_{2}^{s}+D$ where total labor supply (as well as its households components; see below) grows at the natural rate $n$. The split of this labor supply into a floating, a latent, and a stagnant segment must now be formulated in detail in order to complete the model. We thus assume here further that there are upward (inward) and downward (outward) movements between the floating and the latent segments of the labor market. We denote the floating and latent segments as type 1 and type 2 employment, respectively, as indexed above. The unemployment rate in the floating segment is an indicator of the percentage of type 1 workers that are compelled to move into the latent segment and the employment rate of the latent segment is an indicator of the percentage of people who get the chance to move back into the first labor market. This gives rise to the following laws of motion (note that law of motion for $\widehat{L}_{2}^{s}$ is more complex, since there are more flows in and out of this market; the value of $l_{2}^{s}$ can however be determined residually in the following presentation of the model):

$$
\begin{aligned}
\widehat{L}_{1}^{s} & =-\gamma_{1}^{d}\left(1-e_{1}\right)+\gamma_{1}^{u} e_{1}+n, \\
\widehat{D} & =\gamma_{2}^{d}\left(1-e_{2}\right)-\gamma_{2}^{u} e_{2}+n .
\end{aligned}
$$

We have already added here a similar law of motion for the movement in and out of the stagnant segment of the labor market which therefore assumes that there are ways to leave the sphere of pauperism. Yet the downward leading coefficients $\gamma_{1}^{d}, \gamma_{2}^{d}$ will be significantly larger than the upward leading ones $\gamma_{1}^{u}, \gamma_{2}^{u}$. In the steady state we will have

$$
\begin{gathered}
\gamma_{1}^{d}\left(1-e_{1}\right)-\gamma_{1}^{u} e_{1}=0, \\
\gamma_{2}^{d}\left(1-e_{2}\right)-\gamma_{2}^{u} e_{2}=0, \quad \text { i.e. } \\
e_{1}=\frac{\gamma_{1}^{d}}{\gamma_{1}^{d}+\gamma_{1}^{u}}=\frac{1}{1+\gamma_{1}^{u} / \gamma_{1}^{d}}, \\
e_{2}=\frac{\gamma_{2}^{d}}{\gamma_{2}^{d}+\gamma_{2}^{u}}=\frac{1}{1+\gamma_{2}^{u} / \gamma_{2}^{d}} .
\end{gathered}
$$

This suggests that, for plausible values of $e_{1}$, say values greater than $50 \%$, the parameter $\gamma_{1}^{u}$ must be significantly less than $\gamma_{2}^{d}$.

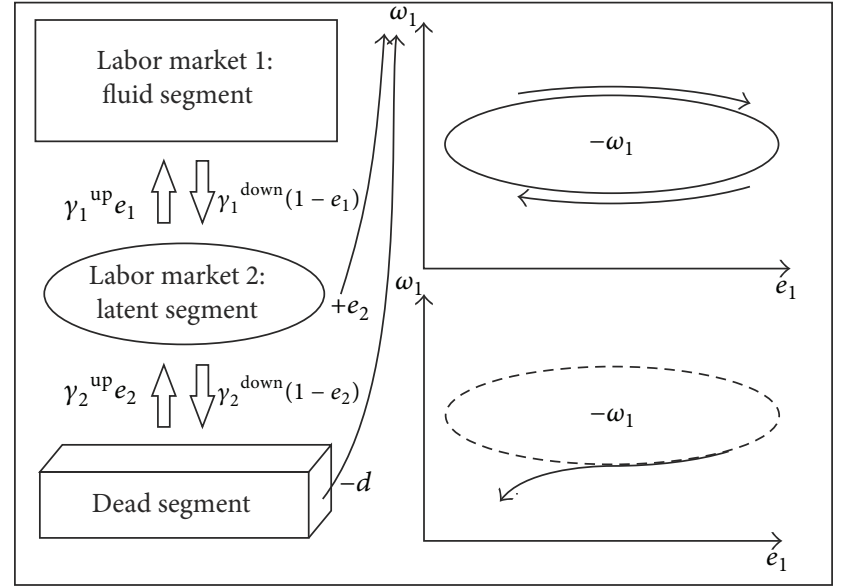

FIGURE 1: The flow of workers between the segments of the labor market.

Taken together we have as laws of motion for this economy with three labor market segments the differential equations (where everything is expressed per unit of capital and denoted in lowercase letters):

$$
\begin{aligned}
& \widehat{\omega}_{1}=\beta_{w e}\left(\frac{\bar{y} / \bar{z}_{1}}{l_{1}^{s}}-\bar{e}_{1}\right)+\beta_{w e_{2}} \frac{\bar{y} / \bar{z}_{2}}{l_{2}^{s}} \\
& -\frac{\beta_{w d} d}{l^{s}}+\beta_{w \omega_{1}}\left(\omega_{1}^{o}-\omega_{1}\right) \\
& \widehat{l}^{s}=n-\bar{y}\left(1-\frac{\omega_{1}}{\bar{z}_{1}}-\frac{\bar{\omega}_{2}}{\bar{z}_{2}}\right), \\
& \widehat{l}_{1}^{s}=-\gamma_{1}^{d}+\left(\gamma_{1}^{d}+\gamma_{1}^{u}\right) \frac{\bar{y} / \bar{z}_{1}}{l_{1}^{s}}+n-\bar{y}\left(1-\frac{\omega_{1}}{\bar{z}_{1}}-\frac{\bar{\omega}_{2}}{\bar{z}_{2}}\right), \\
& \widehat{d}=\gamma_{2}^{d}-\left(\gamma_{2}^{d}+\gamma_{2}^{u}\right) \frac{\bar{y} / \bar{z}_{2}}{l_{2}^{s}}+n-\bar{y}\left(1-\frac{\omega_{1}}{\bar{z}_{1}}-\frac{\bar{\omega}_{2}}{\bar{z}_{2}}\right) \text {, }
\end{aligned}
$$

where the statically endogenous variable $l_{2}^{s}$ is given by $l_{2}^{s}=$ $l^{s}-l_{1}^{s}-d$. This represents a description of the Marxian reserve army mechanism with the three segments of the labor market he assumed as typical for its working under the capitalism of his time.

We summarize the structure of the considered economy by way of Figure 1. Figure 1 shows on its left-hand side the flows occurring between the segments of the labor market which are therefore not completely separated from each other but segmented to a degree that is mirrored through the size $\gamma$ parameters. The top right figure shows an example of a Goodwin-type distributive cycle which will be modified to a convergent dynamics if the real wage barrier term is added to it, here simply visualized by the $-\omega_{1}$-expression in the center of it, the real wage of the workers in the fluid part of the labor market. The arrows in the middle indicate the forces that impact the fluid labor market because of the presence of the other two labor markets, namely, the state of employment in the latent part of the labor market as measures by the employment rate $e_{1}$ and the size of the stagnant segment of 
the labor market, $d$, here measured relative to the size of the capital stock. The size of the first variable has a positive impact on the wage claims made in the fluid labor market while the size of the second one has a negative effect on the wage negotiations. The analysis of the model in subsequent section will show that these feedbacks arising from the lower labor markets onto the dynamics in the first one will add destabilizing forces to the distributive cycle generated in the fluid part of the labor market, as indicated in the bottom right figure.

\section{Steady State and Stability Analysis}

Since we have constructed the dynamics around given parameter values, the steady state, where time derivatives are zero, can easily be determined:

$$
\begin{gathered}
\omega_{1}^{o}=\frac{1-n / \bar{y}}{1 / \bar{z}_{1}+\alpha / \bar{z}_{2}}, \\
e_{1}^{o}=\frac{\gamma_{1}^{d}}{\gamma_{1}^{d}+\gamma_{1}^{u}}, \quad l_{1}^{s o}=\frac{y / \bar{z}_{1}}{e_{1}^{o}}, \\
e_{2}^{o}=\frac{\gamma_{2}^{d}}{\gamma_{2}^{d}+\gamma_{2}^{u}}, \quad l_{2}^{s o}=\frac{y / \bar{z}_{2}}{e_{2}^{o}}, \\
l^{s o}=l_{1}^{s o}+l_{2}^{s o}+d^{o}, \quad \overline{\left(\frac{d}{l}\right)}=\frac{d^{o}}{l^{s o}},
\end{gathered}
$$

where the two latter equations are easily solved for the steady state values of $l^{s}, d$. For the stability of the $4 \mathrm{D}$ dynamical system around this steady state first of all it is important that the determinant of the Jacobian $J^{o}$ at the steady state is positive. This determinant in the case where $d / l$ is unimportant in the wage Phillips curve $\left(\beta_{w d}=0\right)$ is given by

$$
\left|J_{o}\right|=\left|\begin{array}{cccc}
- & - & + & + \\
+ & 0 & 0 & 0 \\
+ & 0 & - & 0 \\
+ & + & - & -
\end{array}\right|
$$

Exploiting the linear dependencies between the various rows of this Jacobian quickly allows the calculation of the determinant of $J^{o}$. The fact that it is positive implies that a loss of stability can only occur by way of the so-called Hopfbifurcation through the death or the birth of an attracting limit cycle (called sub- or supercritical Hopf-bifurcations, resp.).

Feedback chains that may create instability in this way are the two $+\cdots+$ chains shown in the following substructure of $J^{o}$ :

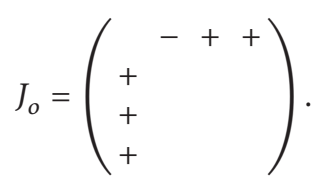

In this particular case we face however no difficulty with respect to the sum of principal minors of order $2, J_{2}$, of the shown Jacobian, since the entries $-J_{21} J_{12}>0$ dominate the sign of $J_{2}$ since they have the weight $l^{\text {so }}$, while the negative off-diagonal products in the last matrix only have weights $l_{1}^{s o}, d^{o}$ with respect to otherwise equal products. The principal minors of order 2 therefore do not create stability problems through the positive feedback chains they contain. Similar arguments can be made with respect to the minors of order 3 , while the ones of order 2 are obviously zero or positive. According to the Routh-Hurwitz theorem this indicates that an increase of the parameter $\beta_{w e_{2}}$ need not endanger the stability of the steady state of the model. This is astonishing, since the terms $J_{14} J_{41}, J_{13} J_{31}$ seem to suggest the opposite.

In Figure 2 we start by showing two-phase plots, a projection into the Goodwin cycle on the first labor market (Figure 2(a)) and a projection of the interactions between the fluid and the dead segment of the labor market (Figure 2(b)). We can see that the Goodwin cycle is now convergent (due to the error correction term in the wage Phillips curve as in Blanchard and Katz [26] in particular), but otherwise of the same kind as the original Goodwin cycle. The dead and the fluid segments in the labor market appear to be largely negatively correlated, as one would expect, so that the dead segment is reduced in extent when the first labor, and with it the second one, is showing higher utilization rates. (The simulations serve mainly illustrative purposes of the theoretical model and do not depend sensitively on specific choices from the economically meaningful parameter space.)

In Figures 2(c) and 2(d) we show two bifurcation diagrams (the bifurcation analyses have been made with the E\&F Chaos software of Diks et al. [27]; the program code and the exact parametrizations, which are not crucial for the qualitative implications as long as staying in an economically meaningful range, can be obtained by the authors upon request; the program applies the Runge-Kutta algorithm to run our continuous-time model with a step-size of $1 / 100$ ) which suggest that increases in the parameter $\beta_{w e_{2}}$ are indeed stabilizing as we have already suggested above. (Note that here transient periods of 30 and 100 years, resp., and a plot of a state variable for 10 years were used. Convergence is however slow; see the vertical scale on the Figure 2(d), where 300 years of transient behavior have been omitted.) Despite the existence of positive feedback loops the interaction of the three labor market segments is therefore not becoming more problematic if the first labor market becomes more sensitive to what happens on the second labor market, where low income work is performed. The same however does not hold true when the impact of the dead segment of the labor market on the wage formation process in the first labor market is increased (by an increasing parameter $\beta_{d}$ ). The positive feedback loop now sits in the first principal minor of order 2, top-left in the matrix $J^{o}$, and thus in the part where multiplication with $l^{\text {so }}$ takes place when the sum of the principal minors is formed:

$$
\left|J_{o}\right|=\left|\begin{array}{cccc}
- & + & 0 & - \\
+ & 0 & 0 & 0 \\
+ & 0 & - & 0 \\
+ & + & - & -
\end{array}\right| \text {. }
$$




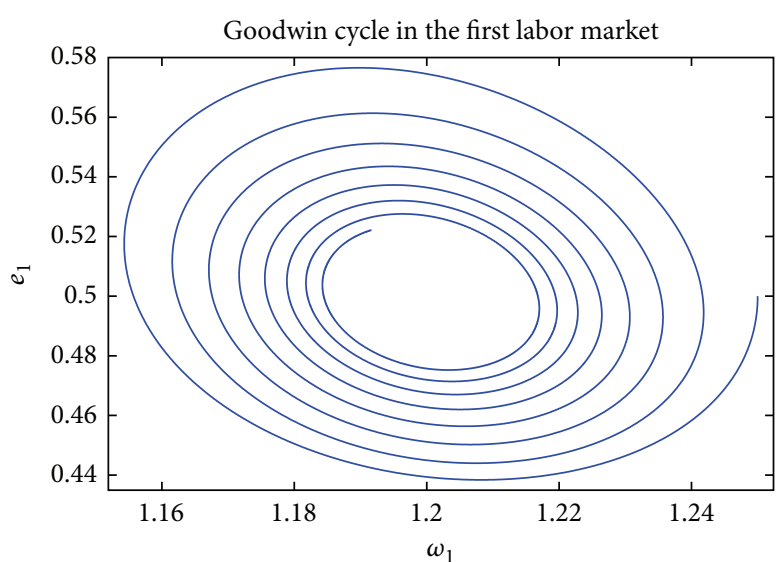

(a)

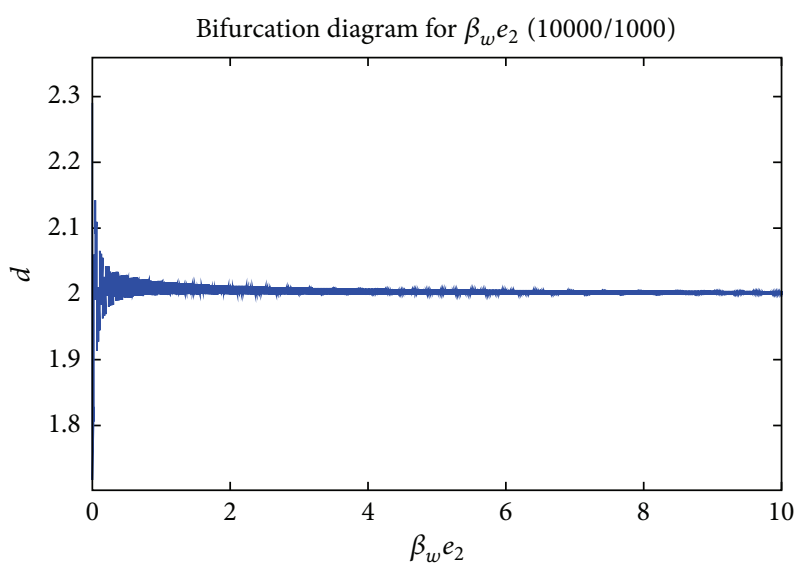

(c)

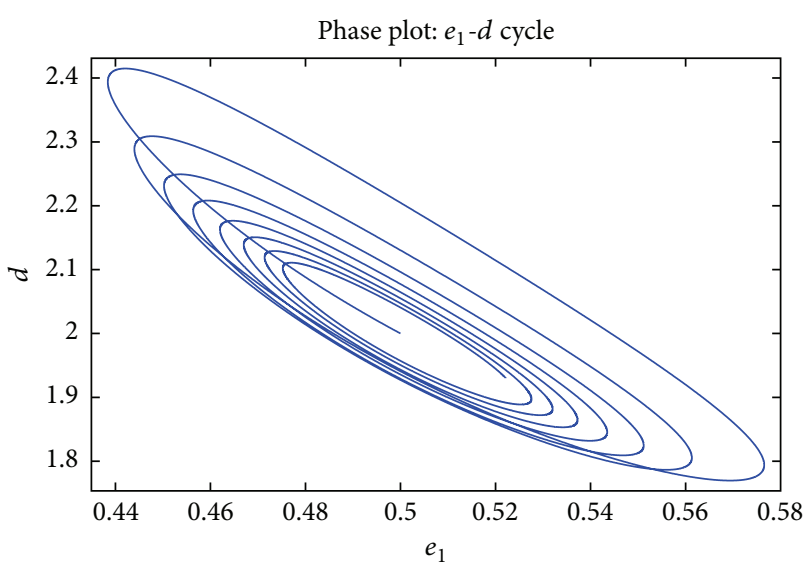

(b)

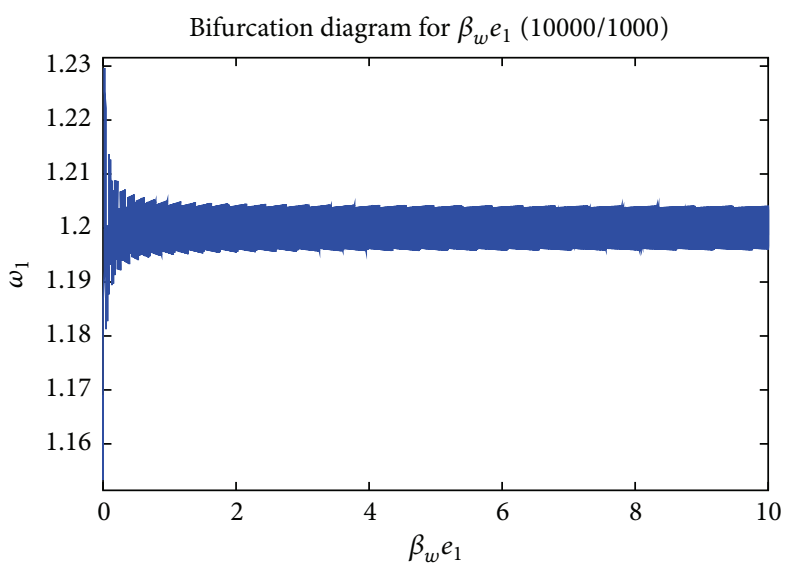

(d)

Figure 2

It therefore dominates the other terms that contain the parameter $\beta_{d}$; see the entries in the matrix shown below, which implies that choosing this parameter sufficiently large will make the considered sum negative and thus violate one of the stability conditions of the Routh-Hurwitz theorem. The dynamics will therefore become an unstable one by way of a sub- or supercritical Hopf-bifurcation in general:

$$
J_{o}=\left(\begin{array}{ll}
+^{+} & - \\
+ &
\end{array}\right) \text {. }
$$

Figure 3(a) shows what we have just discussed in analytical terms. It exemplifies that volatility is increasing by way of a ten-year time window after transient phase of 30 years. With respect to the same time window we also consider such robustness test also for the parameters $\alpha, z_{1}, \gamma_{1}^{d}$. The results for the parameter $z_{2}$ are nearly identical to the ones for the parameter $z_{1}$ and show that labor-saving technical change increases the employment rate in the first labor market. The same holds true for the parameter $\alpha$ which means that improvements in the income of low wage workers do not deteriorate the economic position of the economy. However, increasing the speed with which workers are transmitted from the first into the second labor market does the same thing and provides therefore an example where downward flexibility improves the economy from this partial perspective.

Instability with respect to an increasing role of the dead segment of the labor market in the wage bargain in the fluid labor market is however only one problematic feature of the existence of a dead weight in the labor market. As is well known there are many further social consequences of a large $D$ in the total labor supply $L^{s}$, such as increasing crime, drug consumption, prostitution, and the like. Moreover, political instability may arise from such a segment as Chancellor Bismarck of Germany was one of the first to notice and to pay attention to (as a political leader of his time and from a conservative point of view). From a current German point of view there is however a lack of consciousness among current political leaders of what the long-run consequences of the persistent generation of the so-called Hartz IV families with 


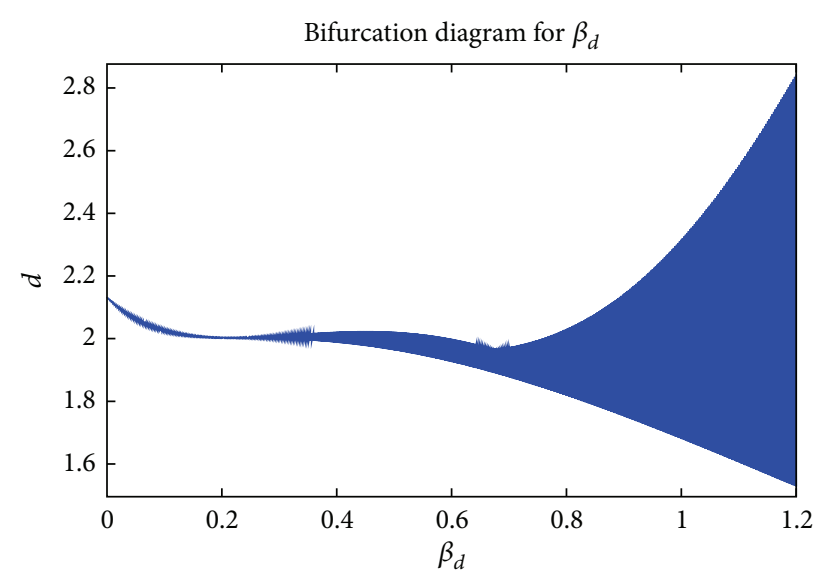

(a)

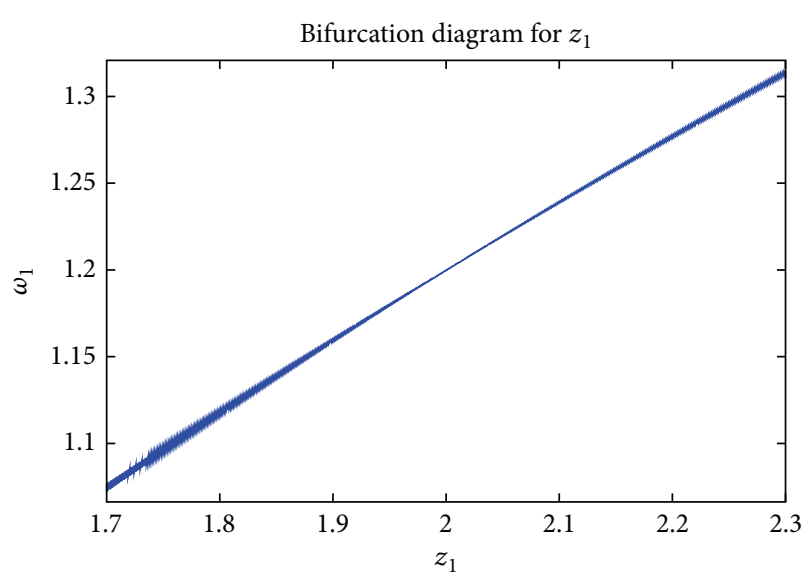

(c)

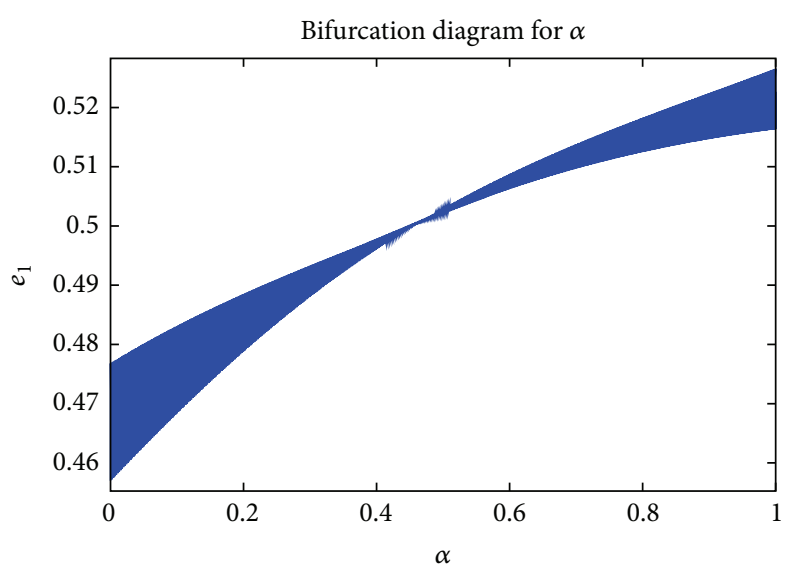

(b)

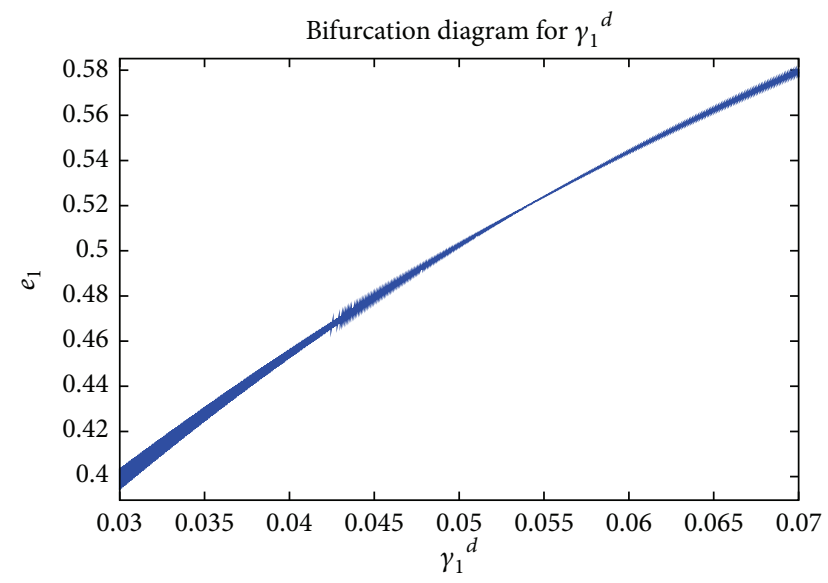

(d)

Figure 3

very low and insecure wage income and very low payments to retired people will be.

\section{Active Labor Market Policy and an Employer of Last Resort}

We have so far considered an economic system with three labor markets, a fluid one (the center economy), a latent one (coming from the periphery), and a stagnant one (where labor supply lives in the slums, where people primarily live on charity through the other members of the workforce whereby part of the latter's consumption demand is simply redistributed). (In the extreme such people have been characterized in Marx "The Eighteenth Brumaire of Louis Napoleon (1852)" as "Lumpenproletariat," the "refuse of all classes," including "swindlers, confidence tricksters, brothelkeepers, rag-and-bone merchants, beggars, and other flotsam of society." We view the third segment of the labor marketwhen increasing-as being on the way to such a social structure, at Marx's times and today related to alcoholism, drug dealing and consuming, youth gang formation, and racism.) This segment of the labor market is however not totally a "stagnant" one, since the parameter $\gamma_{2}^{u}$ provides the extent by which its members can return to the latent segment of the labor market, depending on the rate of employment in this market. Workers employed in this second, latent portion of the labor market receive a given (minimum) real wage, while the fluid labor market works in the way it is assumed to work in the context of models of the distributive cycle. We have abstracted in this extension of the Goodwin model finally from any social legislation and thus have assumed that the unemployed in the two active labor markets are living on the basis of the income of the families they are belonging to, as it is, for example, often the case in Spain and its larger family structures.

In the present section we now not only introduce an unemployment benefit system (augmented by a civic work below) for the two active labor markets of the model but we also assume that the system can be made watertight in the downward direction; that is, the massive generations of a totally degraded workforce are no longer possible in it. Of course, there may exist disabled people of various kinds, but this is not a problem a macromodel has to deal with, so that 
we can simply assume that $\gamma_{2}^{d}=0$ is established through a social network for the unemployed, performing now civic work for the society, civic work which is supervised by the public sector but organized on a private level.

We now consider this second labor market more of the type of a lower income sector, providing the base income corresponding to a basic consumption basket of an advanced capitalist economy but representing "atypical employment," a seemingly necessity in current capitalism where such additions to the permanent staff are demanded by firms (here in the amount $Y\left(\bar{z}_{2}\right)$. Moreover, we postulate that the public sector can demand services (called civic work which may be organized by modern communication techniques through social networks) from the unemployed (who are all receiving unemployment benefits at the base income level just discussed). The organization of these (social) services of course demands microeconomic coordination, with appropriate incentive as well as sanction schemes and with an organizational structure based on electronic networking and the like.

We thus assume now the existence of a public employer of "last resort" who organizes with the help of (electronic) self-organization of the members of the civic work segment the employment (including processes of lifelong learning) of those workers who are not employed by capitalist firms in the first and second labor markets. The public sector thus tries to improve the living conditions in the second labor market as much as possible and administers the funds (received from the workers employed in the first labor market) for the privately unemployed and also conducts a system of social services (in a broad sense of this word) supplied by the "unemployed" (including skill preservation, processes of lifelong learning, and the like).

We are therefore assuming, for the Goodwin model with segmented labor markets $\gamma_{2}^{d}=0$, the existence of sufficient unemployment funds $B$, which are depleted by the current base wage payments $\bar{\omega}_{2}$ to civic work (a historical subsistence wage which is nevertheless significantly "better" than what currently happens in the Hartz IV sector of the German economy) and refunded by taxation of the income of workers at the rate $\tau_{b}$ in the first labor market and the adequate microeconomic organization of civic work which is neutral in its effects with respect to the work done in the private sector of the economy. We are also assuming on this basis that the homogeneity of the universal skills of the total workforce is preserved in this way. Due to this homogeneity of the workforce we can therefore now measure all employment rates in reference to $L^{s}$ solely and thus can express the rate of employment in the civic work sector in residual form by $e_{s}=$ $S / L^{s}=1-e_{1}-e_{2}$. As the model is formulated we have however no "ALG1" payments (unemployment benefits to workers in the first labor market for a limited time period $>\bar{\omega}_{2}$ ), since this would introduce a time structure in unemployment benefits which would increase mathematical complexity, without enriching the considered macrostructure very much. Moreover, since there is no delay in the adjustment of the workforce of firms, an activating labor market policy is not yet a meaningful topic here.
In order to apply this, we start again from the 4D model of unrestricted capitalism:

$$
\begin{gathered}
\widehat{\omega}_{1}=\beta_{w e_{1}}\left(\frac{L_{1}^{d}}{L_{1}^{s}}-\bar{e}_{1}\right)+\frac{\beta_{w e_{2}} L_{2}^{d}}{L_{2}^{s}}-\frac{\beta_{w d} D}{L^{s}}+\beta_{w \omega_{1}}\left(\omega_{1}^{o}-\omega_{1}\right), \\
\widehat{l}^{s}=n-\bar{y}\left(1-\frac{\omega_{1}}{\bar{z}_{1}}-\frac{\bar{\omega}_{2}}{\bar{z}_{2}}\right), \\
\widehat{l}_{1}^{s}=-\gamma_{1}^{d}+\frac{\left(\gamma_{1}^{d}+\gamma_{1}^{u}\right) L_{1}^{d}}{L_{1}^{s}}+n-\bar{y}\left(1-\frac{\omega_{1}}{\bar{z}_{1}}-\frac{\bar{\omega}_{2}}{\bar{z}_{2}}\right), \\
\widehat{d}=\gamma_{2}^{d}-\frac{\left(\gamma_{2}^{d}+\gamma_{2}^{u}\right) L_{2}^{d}}{L_{2}^{s}}+n-\bar{y}\left(1-\frac{\omega_{1}}{\bar{z}_{1}}-\frac{\bar{\omega}_{2}}{\bar{z}_{2}}\right) .
\end{gathered}
$$

With the introduction of civic work the stagnant segment of the labor market has been eliminated by assumption. This implies that $d / l^{s}=0$ has to be replaced by $s / l^{s}, s=S / L^{s}$ with $S$ the current number of civic workers. Based on this, we get as laws of motion for real wages and the labor markets of the economy the following ones ( $\beta_{w d}$ replaced by $\beta_{w s}$ now):

$$
\begin{gathered}
\widehat{\omega}_{1}=\left(\beta_{w e_{1}}+\beta_{w s}\right)\left(e_{1}-\bar{e}_{1}\right)+\left(\beta_{w e_{2}}+\beta_{w s}\right)\left(e_{2}-\bar{e}_{2}\right) \\
+\beta_{w \omega_{1}}\left(\omega_{1}^{o}-\omega_{1}\right), \\
\widehat{l}^{s}=n-\bar{y}\left(1-\frac{\omega_{1}}{\bar{z}_{1}}-\frac{\bar{\omega}_{2}}{\bar{z}_{2}}\right) \text { or } \\
\widehat{e}_{1}=\bar{y}\left(1-\frac{\omega_{1}}{\bar{z}_{1}}-\frac{\bar{\omega}_{2}}{\bar{z}_{2}}\right)-n
\end{gathered}
$$

with

$$
e_{1}=\frac{\bar{y} / \bar{z}_{1}}{l^{s}}, \quad e_{2}=\frac{\bar{y} / \bar{z}_{2}}{l^{s}}=\frac{\bar{z}_{1}}{\bar{z}_{2}} e_{1}, \quad \bar{e}_{2}=\frac{\bar{z}_{1}}{\bar{z}_{2}} \bar{e}_{1},
$$

$\bar{e}_{1}$ exogenously given

$$
\omega_{1}^{o}=\bar{z}_{1}\left(1-\frac{\bar{\omega}_{2}}{\bar{z}_{2}}\right)-n \frac{\bar{z}_{1}}{\bar{y}}, \quad l^{s o}=\frac{\bar{y}}{\bar{z}_{1} \bar{e}_{1}},
$$

where $l^{s o}$ is the steady state solution of (13) and where the steady state value for the real wage is obtained from (14). The fact that $\bar{e}_{1}$ is exogenously given corresponds to the respective negotiation power of the labor and the capital side. As $\bar{e}_{1}$ is a kind of NAIRU that is not inflationary, it can only be achieved by a balance of power between the two production factors. By the choice of the benchmark levels of the employment rates we have adjusted the steady state of the model in principle to the one of the model of unrestricted capitalism (as far as their common features are concerned). Moreover, our modification of the Marxian model has brought us back to the basic format of the Goodwin model, with the stabilizing real wage barrier term in addition now. The model of this section is therefore obviously globally asymptotically stable as exemplified in the simulation of the model shown in Figure 4. 


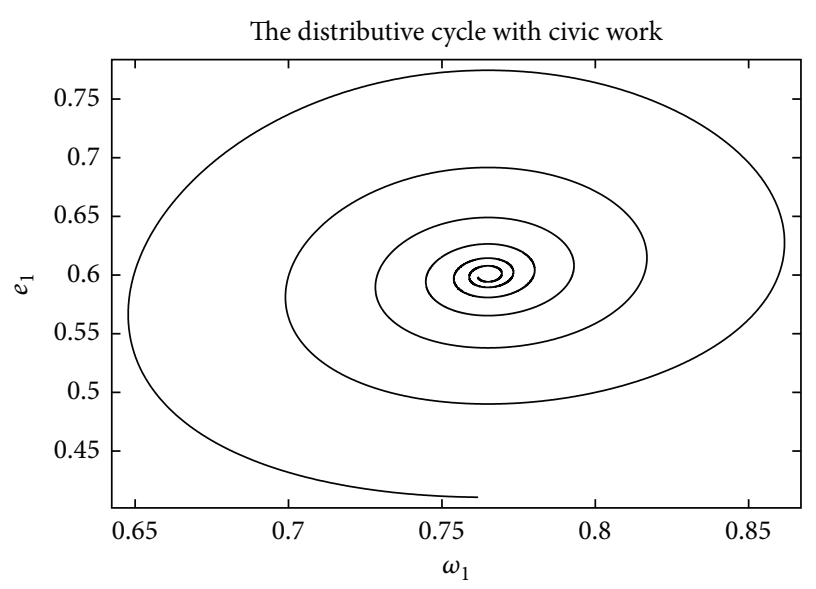

Figure 4: A damped reserve army mechanism in the first labor market.

The elimination of the stagnant segment is achieved by a policy that erects an unemployment benefit system embedded into a civic work structure with reserves $B$ as follows:

$$
\dot{B}=\tau_{b} \omega_{1} L_{1}^{d}-\bar{\omega}_{2}\left(1-\left(e_{1}+e_{2}\right) L^{s}\right)
$$

Workers employed in the first labor market are now taxed with rate $\tau_{b}$ in order to create inflows into the reserves of an unemployment benefit system. The outflow goes to unemployed workers of types 1 and 2 who receive the wage of the employed workers of type 2 as unemployment benefits and have to provide civic work in return (besides their skill preservation activities). This policy at least guarantees skill preservation for workers of types 1 and 2, by employing the $\left(1-e_{1}\right) L_{1}^{s}+\left(1-e_{2}\right) L_{2}^{s}$ workers as an "employer of last resort" in public institutions, which provide social services and more, yet work that is not in competition with the activities occurring in the private sector of the economy. The normal skills of the potentially unemployed people are therefore kept intact at least as suppliers of work of type 2. A labor market reform along these lines thus eliminates the existence of a stagnant segment on the labor market. Nevertheless, we still consider this as very basic reforms of the labor market institutions, yet one that is significantly superior to the Hartz IV system of Germany.

We have for the variable $b=B / K$, the benefit funds per unit of capital, the law of motion:

$$
\begin{aligned}
\dot{b} & =\frac{\dot{B}}{K}-b \widehat{K} \\
& =\frac{\tau_{b} \omega_{1} \bar{y}}{z_{1}}-\bar{\omega}_{2}\left(1-e_{1}-e_{2}\right) l^{s}-\bar{y}\left(1-\frac{\omega_{1}}{\bar{z}_{1}}-\frac{\bar{\omega}_{2}}{\bar{z}_{2}}\right) b \\
& =\left(\tau_{b} \omega_{1} e_{1}-\bar{\omega}_{2}\left(1-e_{1}-e_{2}\right)\right) l^{s}-\bar{y}\left(1-\frac{\omega_{1}}{\bar{z}_{1}}-\frac{\bar{\omega}_{2}}{\bar{z}_{2}}\right) b
\end{aligned}
$$

with $e_{1}=\bar{y} / \bar{z}_{1} / l^{s}, e_{2}=\bar{y} / \bar{z}_{2} / l^{s}$. In the steady state this gives

$$
b^{o}=\frac{\left(\tau_{b} \omega_{1}^{o} \bar{e}_{1}-\bar{\omega}_{2}\left(1-\bar{e}_{1}-\bar{e}_{2}\right)\right) l^{s o}}{n} .
$$

This expression shows that the parameters of the model have to be determined with care such that the wage income after taxes of households of type 1 is of an appropriate size. Moreover, the law of motion for $b$ is a stable one as long as the prerequisite of a converging core model (see (13)-(14)) is met.

The case of Germany in recent decades provides an example where things went wrong eventually after a long postwar prosperity phase due to a lack of cooperating corporatism between capital and labor primarily in the question of income distribution. It is shown in Flaschel and Greiner [25] that adding minimum real wages as well as maximum ones to the distributive cycle can reduce its amplitude significantly both in the prosperity phase and the depressed phase. The reserve army of unemployed thus thereby is reduced in the depression and the social degradation of part of the workforce avoided. But in the prosperity phase, unions in Germany did not think in terms of Marx's reserve army mechanism and did not consider ceilings to their real wage claims. Chancellor Willy Brandt supported indirectly this behavior when he proclaimed that full employment would now be maintained forever. But Marx's overshooting income claims mechanism worked in this context (leading first to stagflation and later on to stagnation without inflation). By contrast, minimum real wage legislation was not taken seriously after the Iron Curtain came down, neither by the social democrats who under Chancellor Schröder implemented the Hartz I-IV reforms nor under Chancellor Merkel where the discussion about minimum wages was only conducted from a very microeconomic perspective. The result of such policies was the establishment of a progressively increasing low-income or part-time labor market segment and from there the flow of workers into Hartz VI which can by and large be considered a stagnant segment from the perspective of the social standards of the fluid segment of the labor markets in Germany.

These policies opened watergates on the labor market into a downward direction and contributed significantly to a return of a labor market structure as investigated already by Marx [23] in Capital, Vol. I, and modeled in this paper. Lacking insights into the Marxian reserve army mechanism on both sides of the conflict about income distribution (concerning agreements on both maximum and minimum real wages) as well as on both sides of the political spectrum in Germany (concerning resistance to processes of social degradation within the workforce) have now led in Germany to a situation where processes of social segmentation are difficult to overcome (even if policy would be willing to act accordingly).

The 1960s and early 1970s (where the Marxian insight into the working of capitalism and the reserve army mechanism was totally neglected) can thus be considered as a time of lost chances, since maximum and minimum real wages are easier to negotiate and implement by law in prosperity phases. To a certain degree the consequences of this failure 
was the disintegration of the concepts that constituted the German way to a "social market economy" into the direction of low-income work and widespread poverty and its social consequences.

\section{Historical Origins and Political Perspectives}

5.1. Social Legislation under Bismarck. The unrestricted working of the distributive cycle is not a viable way an advanced capitalist economy can reproduce itself in the long run. We conclude that from what is shown in Figures 3(a)3(d) and in the analysis accompanying it. The first person who became fully aware of this fundamental problem of capitalism on the side of the ruling classes was definitely Otto von Bismarck, Prime Minister in Prussia (appointed in 1862), and later on Chancellor in the German Empire which was founded in 1871 with Wilhelm I as first German emperor (and king of Prussia). When the last German emperorWilhelm II-came into power in 1888, the time of Bismarck as politically influential German chancellor was soon over, since Wilhelm II intended to make his own type of in fact internationally and nationally unbalanced policy. Bismarck thus resigned from his chancellorship in 1890.

The social legislation initiated by Bismarck was by no means an act of humanism, but a reflected strategic reaction to the social movements which the conflict between capital and labor in the sphere of production and about income distribution had created. A similar observation may hold for the Cold War period after World War II, while the opposite happened after the fall of the Iron Curtain in the 1990s, which was preceded however by Reaganomics and Thatcherism in the 1980s in the Anglo-Saxon world as a reaction to the stagflation of the 1970s. These latter deregulation policies did not at all pay attention to the social consequences they caused (compared to the prosperity phase after WWII).

Otto von Bismarck was born as a member of the Prussian landed aristocracy and after his education soon became part of the Prussian parliament as a conservative. As chancellor of the new Empire, Bismarck soon started to deal with social legislation though his first domestic measures were aimed at the role of the Catholic church and its influence. These actions are known as "Kulturkampf" and can be regarded as part of secularization though this was not the aim. A main success was the introduction of "civil marriage" but the results of the "Kulturkampf" were not generally successful with regard to the influence of political parties. One of Bismarck's aims had been to reduce the influence of the Catholic-oriented parties, such as the German Center Party. Therefore he even cooperated with the liberal parties in spite of significant areas of disagreement.

The failed revolution of 1848 as well as the social situation of the working class had raised the interest in the population of the German states in social issues, although the 1848 revolution was mainly part of a civil movement with the aim of a German unification. But after 1848, the first worker unions were established and socialist parties were founded, partly related to the ideas of Karl Marx. Thus, an important working class movement could develop with socialist parties, unions, and other working class organizations with the intention to improve the economic and social situation of the workers. Bismarck succeeded in 1878 to implement an "antisocialist law" with the help of conservative and nationalliberal parties, but the socialist movement nevertheless grew stronger so that the law was not renewed in 1890. Bismarck's best known and certainly most important decisions were the implementation of the world's first social legislations. Those are supposed to have been established not only due to the insight into the necessity for the state to improve the burdensome lot of workers, but also due to the fact of the increasing influence of the social-democratic party. Bismarck hoped to reduce this influence by introducing several social laws. These were mainly insurance bills so that the workers of the economy were not left unprotected (see Federal Statistical Office [4] and van Meerhaeghe [28]). Bismarck was aware of the bad working conditions and willing to improve them but wanted at the same time to avoid regulations that could harm the economy.

Three areas of risk were regulated starting with the Health Insurance for part of the workers in 1883 which was transferred into Health Insurance Act for most of the workers. This is the starting point of Medical Care in Germany. The Health Insurance was financed by contributions of employees (twothirds of the sum) and employers (one-third of the sum). In 1884, The Accident Insurance Act followed which was of high relevance especially for workers in particularly dangerous establishments. This insurance was paid by employers who otherwise had to pay for workers who suffered an accident. The Law of Invalidity and Old Age Insurance for workers, journeymen, and apprentices was the third social law in 1889 which was the starting point of a general old age pension insurance. Employers and employees had to pay each half of the costs which was also subsidized by the state (see Holborn [29]). Thus, the social security legislation which was implemented by Bismarck can without doubt be regarded as a first step towards a welfare state though the situation of working families remained difficult in the 19th century.

It was criticized as "Staatssozialismus" especially by the liberals but in 1881 Bismarck even made a prediction:

\section{It is possible that our policy may be reversed at some future time when I am dead; but State Socialism will make its way. (Busch 1898)}

There are also reasons for the remaining bad situation of workers to be found in Bismarck's social laws themselves, since, for example, not all workers were included in the three laws and not all possible cases were considered, at least not at the beginning. Other critical points are related to the fact that the Old Age Program allowed only payment after 30 years of work and not before the age of 70 though the average age expectation was below 50 at that time. As Khoudour-Castéras [30] shows, there was a notable positive effect of the social legislation with regard to the German emigration (mainly to the United States) since many Germans now decided to abandon their migration plans.

5.2. Civic Work as a Key Factor of Future Labor Market Policy. Social legislation (based on democratic principles) may be the 
prerequisite to put workers, who were lost and deprived of their skills in the dead segment under unregulated capitalism, back to a meaningful occupation with adequate living conditions. We will deal with the question of what such a social legislation can look like to guarantee (re)integration into work life and the society and to create a positive perception for those people employed through an active labor market policy.

Active labor market policy must be conducted complementarily to the presence of free market hiring and firing in the fluid segment of the labor market. It is not meant to crowd out skilled workers of the first segment but to provide a safety net for those kicked out due to the business cycle component in macroeconomic development. Besides the social benefits arising from an appropriate social legislation, skill preservation is the second major function of the civic work system to be established. If a worker becomes unemployed in the competitive first labor market, she should be immediately supported by a governmental labor market agency to secure her income by unemployment benefits. Unemployment benefits could be paid out of a kind of insurance scheme as it is done today in Germany. When she is no longer entitled to receive them after a while and has not found a new job, she might enter the civic work program offered to everybody by the state. It can be tax-financed by the workers occupied in the fluid segment who will likely have a rather high income on average. Of course, this is only one possible financing scheme, actually the one used in our formal model. This way of financing is chosen for the sake of keeping the model simple and to avoid unnecessary complications. But from societal point of view it might also be opportune to tax firms' profits as well.

Payments in the civic work program might no longer depend on previous income but are equal for everyone, though they should take into account family backgrounds. Summarizing, one can briefly outline the principles and objectives of civic work as follows: civic work has to be conducted in a tit-for-tat manner, which means that support by the state is granted in exchange for an obligation to work. This principle must be applied to the extent the participants of the program are actually able to work. The term workfare has been discredited in recent times but might capture the principle quite well as long as it is understood in a technical way.

One of the main advantages of a civic work system is that it stops stigmatizing unemployed people. Under civic work the formerly unemployed people would contribute their part to the community. Lifelong learning is a major ingredient of the civic work proposal to preserve and even enhance the skills of individual workers. This can be achieved by employing those skills in a meaningful way to the benefit of the community and give all participants the opportunity to adjust their set of skills to the demand of potential employers in order to raise the probability of matching in the competitive labor markets.

The matching problem has to be solved not only in the first labor market, but in the area of civic work too. The society is in need of several services not provided by the market. Civic workers who are willing and capable of delivering those services must be assigned to the respective "jobs." As it turns out, this is also a matching problem which does not have to be solved top-down by a governmental authority, but in an intelligent bottom-up way. Means brought up by the information society might be of not underestimated help here.

This brings us naturally to the question of how to organize civic work. As already mentioned a guiding iron principle in contrast to former concepts of "workfare" must be to organize civic work as a bottom-up approach and not top-down in an authoritarian way. The government could introduce and use, for example, e-civic-work online platforms to support the matching process of skills due to a demand and supply principle. Government might provide some of the resources for this allocation device but should allow for selforganization of the virtual marketplaces. The platform should be run on a nonprofit basis (this is something different than commercial social platforms like Facebook and the like). It can be programmed and maintained (as well as improved) by civic workers with appropriate qualifications.

Also voluntary input is possible: that means it is open to contributions from everyone and thus remains in the public domain. There are existing successful examples for open source (public domain) projects like the LaTex community, which has provided a high-standard software tool for academic paper-type setting for years with permanent improvements.

Possible civic work services include, for instance, the schooling of adults as part of lifelong learning and skill preservation and enhancement, care for the elderly or children with respect to additional services which are not provided under competitive market conditions, community projects of all kinds (which could not be financed otherwise), which demand a wide range of contributions from construction work to service in libraries, engagement in community politics, support of local sports clubs, and many more.

However, a crucial point which is not to be neglected is the question of the transition to such a system of civic work. If a government should decide to implement civic work as we have put it forth, no master plan would be needed. Some rules at the beginning would provide for an "organic" generation of a robust and efficient civic work system. The government would have to give organizational principles when pursuing the goal of establishing civic work as we understand it. Guidelines and basic rules are needed, but no planning in detail from top. Self-organizing and learning by doing are from an evolutionary point of view superior principles to design any kind of such an admittedly complex system.

\section{Conclusions}

In this paper, we started from a baseline version of the Goodwin [1] model of the distributive cycle which describes the implications of the reserve army mechanism of capitalist economies. We have added to this model segmented labor markets as described in Marx's Capital, Vol. I. The models exhibited a unique steady state solution which depends on the speeds with which workers are pushed into or out of 
the labor market segments. We investigated the stability properties of this model and found that, though there was a stabilizing inflation barrier term in our wage Phillips curve, the interaction between the latent and the stagnant portions of the labor market generated potentially destabilizing forces.

We then introduced an active labor market policy where government acts as employer of last resort, thereby eliminating the stagnant portion of the labor market, whilst erecting an unemployment benefit system that sustains the incomes of workers that leave the floating labor market into the latent one. We showed that this policy guarantees the macrostability of the economy's growth path. However, the affordability of such a structure needs a certain level of real wages and thus should be embedded into a model where there is growth of labor productivity. In such a system, where full employment is guaranteed, concerns about inflationary pressures should however be taken into account; see Desai [31] for its initial treatment in the Goodwin model. We have therefore proposed a wage Phillips curve where elements of cautiousness are incorporated in a simple way, suggesting that more reflection is needed in order to design a wage management system that avoids strong inflationary pressure in the boom and that eschews the danger of deflation during recessions.

In the model of this paper, we have assumed Say's law and considered mainly the supply-side dynamics of the economy. It would be interesting, as an area of future research, to consider demand-side implications of introducing civic work through an "employer of last resort." We postulate that the introduction of the demand-side channel, together with the appropriate policy refinement, will further add some stabilizing force that will minimize the amplitude of the business cycle. Furthermore, the consideration of the demandside will provide a proper framework through which the effects of various interventions on economic performance, for example, civic work versus the Basic Income Grant, are compared.

Finally, we conclude that a reformed type of capitalism may be working much better compared to the unrestricted one, normally justified by international competitiveness pressures, where labor market segmentation can give rise to big economic and social problems. These problems can range from loss of social cohesion to social conflict and political instability.

\section{Appendix}

\section{Stability of Balanced Growth}

In this section we investigate the stability properties of the Marxian growth cycle model with the segmented labor markets which we have formulated above. We thus reconsider again the $4 \mathrm{D}$ autonomous system given by

$$
\begin{aligned}
\widehat{\omega}_{1}= & \beta_{w e_{1}}\left(\frac{\bar{y} / \bar{z}_{1}}{l_{1}^{s}}-\bar{e}_{1}\right)+\beta_{w e_{2}} \frac{\bar{y} / \bar{z}_{2}}{l^{s}-l_{1}^{s}-d}-\frac{\beta_{w d} d}{l^{s}} \\
& +\beta_{w \omega_{1}}\left(\omega_{1}^{o}-\omega_{1}\right)
\end{aligned}
$$

$$
\begin{gathered}
\widehat{l}^{s}=n-\bar{y}\left(1-\frac{\omega_{1}}{\bar{z}_{1}}-\frac{\bar{\omega}_{2}}{\bar{z}_{2}}\right), \\
\widehat{l}_{1}^{s}=-\gamma_{1}^{d}+\left(\gamma_{1}^{d}+\gamma_{1}^{u}\right) \frac{\bar{y} / \bar{z}_{1}}{l_{1}^{s}}+n-\bar{y}\left(1-\frac{\omega_{1}}{\bar{z}_{1}}-\frac{\bar{\omega}_{2}}{\bar{z}_{2}}\right), \\
\widehat{d}=\gamma_{2}^{d}-\left(\gamma_{2}^{d}+\gamma_{2}^{u}\right) \frac{\bar{y} / \bar{z}_{2}}{l^{s}-l_{1}^{s}-d}+n-\bar{y}\left(1-\frac{\omega_{1}}{\bar{z}_{1}}-\frac{\bar{\omega}_{2}}{\bar{z}_{2}}\right) .
\end{gathered}
$$

Since linear dependent expressions cancel in the calculation of the determinant of the Jacobian of this system at the steady position, we can simplify the right-hand side of these equations as follows, without changing the sign of the determinant of this Jacobian:

$$
\begin{gathered}
\widehat{\omega}_{1}=\beta_{w e_{1}}\left(\frac{\bar{y} / \bar{z}_{1}}{l_{1}^{s}}-\bar{e}_{1}\right)+\beta_{w e_{2}} \frac{\bar{y} / \bar{z}_{2}}{l^{s}-l_{1}^{s}-d}-\frac{\beta_{w d} d}{l^{s}}, \\
\widehat{l}^{s}=\omega_{1}, \\
\widehat{l}_{1}^{s}=\left(\gamma_{1}^{d}+\gamma_{1}^{u}\right) \frac{\bar{y} / \bar{z}_{1}}{l_{1}^{s}} \\
\widehat{d}=-\left(\gamma_{2}^{d}+\gamma_{2}^{u}\right) \frac{\bar{y} / \bar{z}_{2}}{l^{s}-l_{1}^{s}-d} .
\end{gathered}
$$

After further reductions we arrive at the following form of a truncated Jacobian of this dynamical system:

$$
J_{o}=\left(\begin{array}{cccc}
0 & \frac{d}{\left(l^{s}\right)^{2}} & 0 & -\frac{1}{l^{s}} \\
1 & 0 & 0 & 0 \\
0 & \frac{1}{\left(l^{s}-d\right)^{2}} & 0 & -\frac{1}{\left(l^{s}-d\right)^{2}} \\
0 & 0 & \frac{1}{\left(l^{s}\right)^{2}} & 0
\end{array}\right) .
$$

This gives for the determinant of this Jacobian the expression

$$
J_{o}=\frac{\left(-d / l^{s}+1\right)}{\left[\left(l^{s}\right)^{3}\left(l^{s}-d\right)^{2}\right]}=\frac{\left(1-d / l^{s}\right)}{\left[\left(l^{s}\right)^{3}\left(l^{s}-d\right)^{2}\right]}>0
$$


With respect to the other stability conditions we have to consider the sign distribution within the Jacobian of the dynamical system:

$$
\begin{gathered}
\widehat{\omega}_{1}=\beta_{w e_{1}}\left(\frac{\bar{y} / \bar{z}_{1}}{l_{1}^{s}}-\bar{e}_{1}\right)+\beta_{w e_{2}} \frac{\bar{y} / \bar{z}_{2}}{l^{s}-l_{1}^{s}-d}-\frac{\beta_{w d} d}{l^{s}} \\
+\beta_{w \omega_{1}}\left(\omega_{1}^{o}-\omega_{1}\right), \\
\widehat{l}^{s}=n-\bar{y}\left(1-\frac{\omega_{1}}{\bar{z}_{1}}-\frac{\bar{\omega}_{2}}{\bar{z}_{2}}\right), \\
\widehat{l_{1}^{s}}=-\gamma_{1}^{d}+\left(\gamma_{1}^{d}+\gamma_{1}^{u}\right) \frac{\bar{y} / \bar{z}_{1}}{l_{1}^{s}}+n-\bar{y}\left(1-\frac{\omega_{1}}{\bar{z}_{1}}-\frac{\bar{\omega}_{2}}{\bar{z}_{2}}\right), \\
\widehat{d}=\gamma_{2}^{d}-\left(\gamma_{2}^{d}+\gamma_{2}^{u}\right) \frac{\bar{y} / \bar{z}_{2}}{l^{s}-l_{1}^{s}-d}+n-\bar{y}\left(1-\frac{\omega_{1}}{\bar{z}_{1}}-\frac{\bar{\omega}_{2}}{\bar{z}_{2}}\right)
\end{gathered}
$$

which is given by

$$
J_{o}=\left(\begin{array}{cccc}
- & ? & ? & ? \\
+ & 0 & 0 & 0 \\
+ & 0 & - & 0 \\
+ & + & - & -
\end{array}\right)
$$

If the first term in the Phillips curve is dominating the second and the third one with respect to the state variable $l^{s}, l_{2}^{s}, d$ so that the floating part dynamics of the model is in particular of the type of a Goodwin cycle $J_{12}<0$ (with damped oscillations however) we in particular get (in order to get this result the conditions $\beta_{w e_{1}}\left(\bar{z}_{2} / \bar{z}_{1}\right)\left(l_{2}^{s} / l_{1}^{s}\right)^{2}>\beta_{w e_{2}}$,

$\beta_{w e_{1}}\left(\bar{y} / z_{1}\right)\left(l^{s} / l_{1}^{s}\right)^{2}, \beta_{w e_{1}}\left(\bar{y} / z_{1} l^{s}\right)\left(l^{s} / l_{1}^{s}\right)^{2}>\beta_{w d}$ must hold; however, other cases with other stability properties are possible and thus make the outcome of this model of unrestricted capitalism somewhat ambiguous)

$$
J_{o}=\left(\begin{array}{cccc}
- & - & + & + \\
+ & 0 & 0 & 0 \\
+ & 0 & - & 0 \\
+ & + & - & -
\end{array}\right)
$$

In addition to the stability result obtained above we see further stabilizing feedback channels at work. In the Goodwin subdynamics, that is, the interaction of the state variables $\omega_{1}, l^{s}$, we have again the result of the distributive cycle without segmented labor markets. There are however also destabilizing feedback chains at work now. There is first the cumulative interaction of $d, \omega_{1}$ in the laws of motion of real wages and of the stagnant segment of the labor market. And secondly, there is the cumulative interaction between the state variables $l_{1}^{s}, \omega_{1}$ in the laws of motion for real wages and the latent segment of the labor market. Of course all these statements are made from a partial perspective concerning the principal minors of order 2 of the Jacobian $J$ solely. There are no destabilizing adjustment processes in the trace of $J$. We however conclude from these observations that the stable Goodwin growth cycle within the floating element of the labor market is plagued by some positive feedback chains caused by the existence of the latent and the stagnant part of the labor market and their interaction with the real wage dynamics in particular. Should these feedback chains make the overall dynamics unstable, this will occur by way of a Hopf bifurcation, through the death or birth of unstable or stable limit cycles, respectively, since the determinant of the system cannot change its sign; that is, the roots of the Jacobian can only enter the positive part of the complex plane of complex numbers by becoming complex at the bifurcation point. The loss of stability therefore necessarily occurs in the presence of business fluctuations.

\section{Conflict of Interests}

The authors declare that there is no conflict of interests regarding the publication of this paper.

\section{Acknowledgments}

The authors would like to thank two anonymous referees for their constructive critique and participants of the joint OECD-Open University conference "New Directions in Welfare" in Paris, July 3-5, 2013, and the Research Network Macroeconomics and Macroeconomic Policies (FMM) conference in Berlin, October 24-26, 2013, for valuable comments.

\section{References}

[1] R. M. Goodwin, "A growth cycle," in Socialism, Capitalism and Economic Growth, C. H. Feinstein, Ed., pp. 54-558, Cambridge University Press, Cambridge, UK, 1967.

[2] U. Blien, U. Walwei, and H. Werner, "Labour market policy in Germany. Job placement, unemployment insurance and active labour market policy in Germany"' in Active Labor Market Policies and Unemployment Insurance in Selected Countries, K. S. Yoo and J. Chang, Eds., pp. 225-285, Korea Labor Institute and Friedrich-EbertStiftung, Seoul, Republic of Korea, 2002.

[3] W. Tompson, The Political Economy of Reform: Lessons from Pensions, Product Markets and Labour Markets in Ten OECD Countries, OECD Publishing, 2009.

[4] Federal Statistical Office, Eckzahlen zum Arbeitsmarkt, Federal Statistical Office, Wiesbaden, Germany, 2011.

[5] Eurofound, "Bismarck's Social Security Legislation," 2009, http://www.eurofound.europa.eu/emire/GERMANY/ BISMARCKSSOCIALSECURITYLEGISLATION-DE.htm.

[6] G. Bosch and T. Kalina, "Low-wage work in Germany: an overview," in Low-Wage Work in Germany, G. Bosch and C. Weinkopf, Eds., pp. 19-112, Russel Sage Foundation, New York, NY, USA, 2008.

[7] R. Solow, "The German story (Introduction)," in Low-Wage Work in Germany, G. Bosch and C. Weinkopf, Eds., pp. 1-18, Russel Sage Foundation, New York, NY, USA, 2008.

[8] G. Bosch and C. Weinkopf, Low-Wage Work in Germany, Russel Sage Foundation, New York, NY, USA, 2008.

[9] "Bundesagentur für Arbeit: Monatsbericht Dezember und Jahr," 2010, http://statistik.arbeitsagentur.de/cae/servlet/contentblob/ 240798/publicationFile/115650/Monatsbericht-201012.pdf.

[10] R. Solow, "A contribution to the theory of economic growth," Quarterly Journal of Economics, vol. 70, pp. 65-694, 1956. 
[11] P. Flaschel, Macrodynamics. Elements for a Synthesis of Marx, Keynes and Schumpeter, Springer, Heidelberg, Germany, 2009.

[12] R. Solow, "Goodwin's growth cycle: reminiscence and rumination," in Nonlinear and Multisectoral Macrodynamics, K. Velupillai, Ed., pp. 31-41, Macmillan, London, UK, 1990.

[13] N. Barbosa-Filho and L. Taylor, "Distributive and demand cycles in the US economy-a structuralist Goodwin model," Metroeconomica, vol. 57, pp. 389-411, 2006.

[14] L. Taylor, Reconstructing Macroeconomics. Structuralist Proposals and Critique of the 24 Mainstream, Harvard University Press, Cambridge, Mass, USA, 2004.

[15] P. Flaschel and M. Landesmann, "Richard Murphey Goodwin (1913-1996): his legacy continued," Structural Change and Economic Dynamics, vol. 17, no. 4, pp. 379-381, 2006.

[16] P. Flaschel and M. Landesmann, Mathematical Economics and the Dynamics of Capitalism. The Legacy of Richard Goodwin Continued, Routledge Frontiers of Political Economy, London, UK, 2008.

[17] D. Harvie, "Testing Goodwin: growth cycles in the OECD countries," Cambridge Journal of Economics, vol. 24, no. 3, pp. 349-376, 2000.

[18] R. Veneziani and S. Mohun, "Structural stability and Goodwin's growth cycle," Structural Change and Economic Dynamics, vol. 17, no. 4, pp. 437-451, 2006.

[19] S. Mohun and R. Veneziani, "Goodwin cycles and the US economy, 1948-2004," in Mathematical Economics and the Dynamics of Capitalism. The Legacy of Richard Goodwin Continued, P. Flaschel and M. Landesmann, Eds., Routledge Frontiers of Political Economy, London, UK, 2008.

[20] R. Franke, P. Flaschel, and C. R. Proaño, "Wage-price dynamics and income distribution in a semi-structural Keynes-Goodwin model," Structural Change and Economic Dynamics, vol. 17, no. 4, pp. 452-465, 2006.

[21] C. Fiorio, S. Mohun, and R. Veneziani, "Social democracy and distributive conflict in the UK, 1950-2010," Working Paper 705, School of Economics and Finance, Queen Mary University of London, 2013.

[22] R. M. Goodwin, "A growth cycle," in A Critique of Economic Theory, E. K. Hunt and J. G. Schwartz, Eds., pp. 442-449, Penguin Books, Harmondsworth, UK, 1972.

[23] K. Marx, Capital, Volume I, Lawrence and Wishart, London, UK, 1954

[24] J. Glombowski and M. Krüger, "Unemployment insurance and cyclical growth," in Nonlinear Models of Fluctuating Growth, R. Goodwin, M. Krüger, and A. Vercelli, Eds., pp. 25-46, Springer, Heidelberg, UK, 1984.

[25] P. Flaschel and A. Greiner, "Employment cycles and minimum wages. A macro view," Structural Change and Economic Dynamics, vol. 20, no. 4, pp. 279-287, 2009.

[26] O. Blanchard and L. F. Katz, "Wage dynamics: reconciling theory and evidence," The American Economic Review, vol. 89, no. 2, pp. 69-74, 1999.

[27] C. Diks, C. Hommes, V. Panchenko, and R. van der Weide, "E\&F chaos: a user friendly software package for nonlinear economic dynamics," Computational Economics, vol. 32, no. 1-2, pp. 221244, 2008.

[28] M. van Meerhaeghe, "Bismarck and the social question," Journal of Economic Studies, vol. 33, no. 4, pp. 284-301, 2006.

[29] H. Holborn, A History of Modern Germany, Volume III, Princeton University Press, Princeton, NJ, USA, 1969.
[30] D. Khoudour-Castéras, "Welfare state and labor mobility: the impact of Bismarck's social legislation on German emigration before World War I," Journal of Economic History, vol. 68, no. 1, pp. 211-243, 2008.

[31] M. Desai, "Growth cycles and inflation in a model of the class struggle," Journal of Economic Theory, vol. 6, no. 6, pp. 527-545, 1973. 

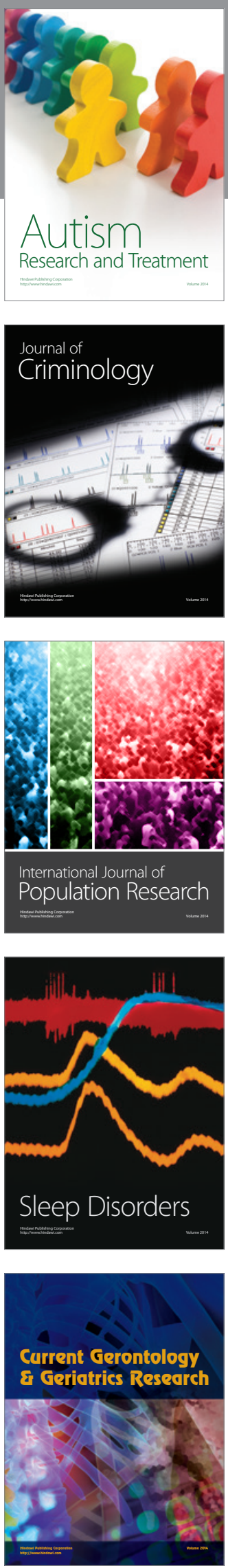
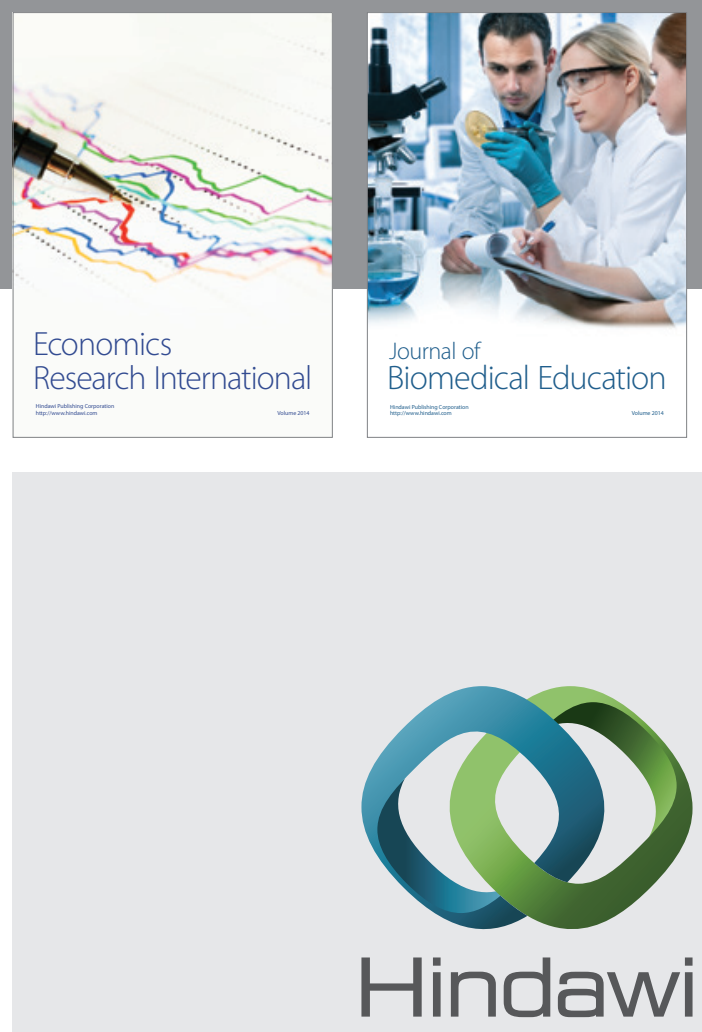

Submit your manuscripts at

http://www.hindawi.com
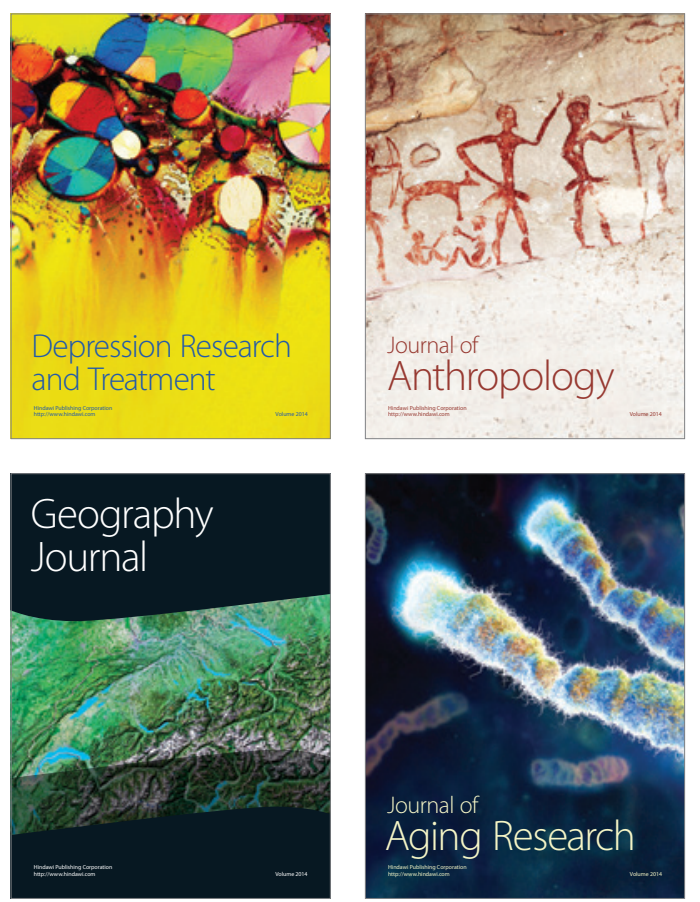
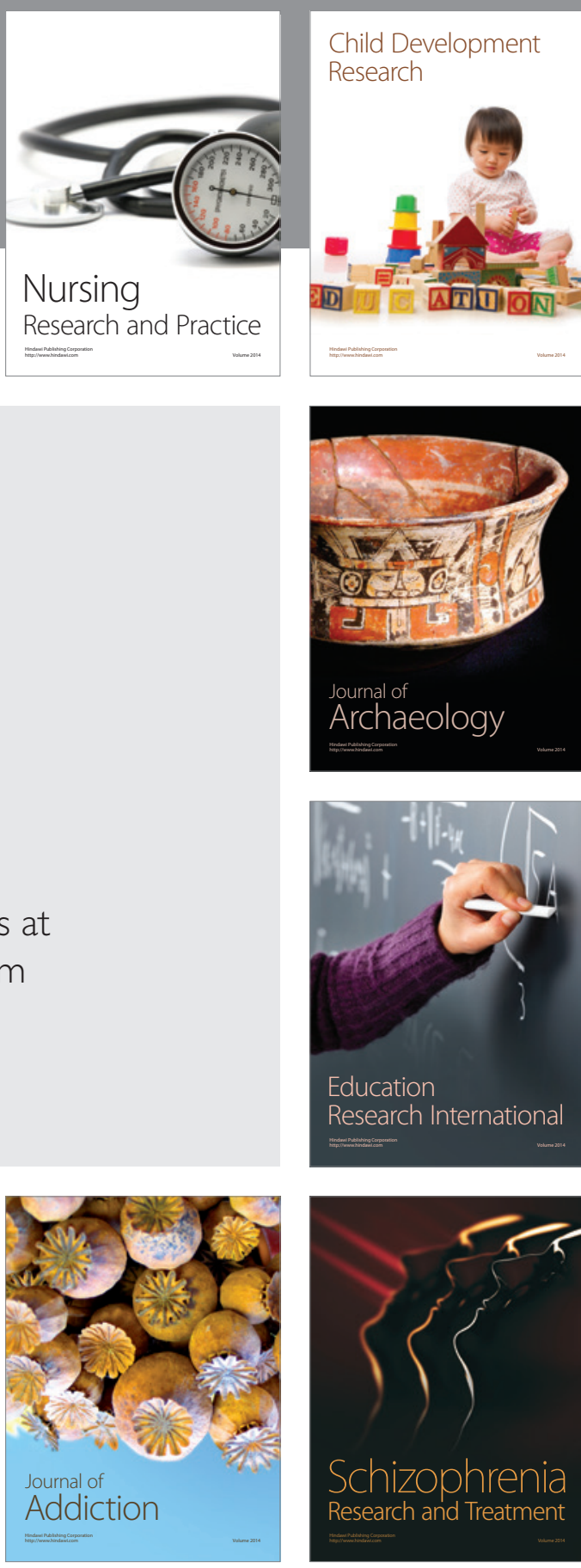

(D)
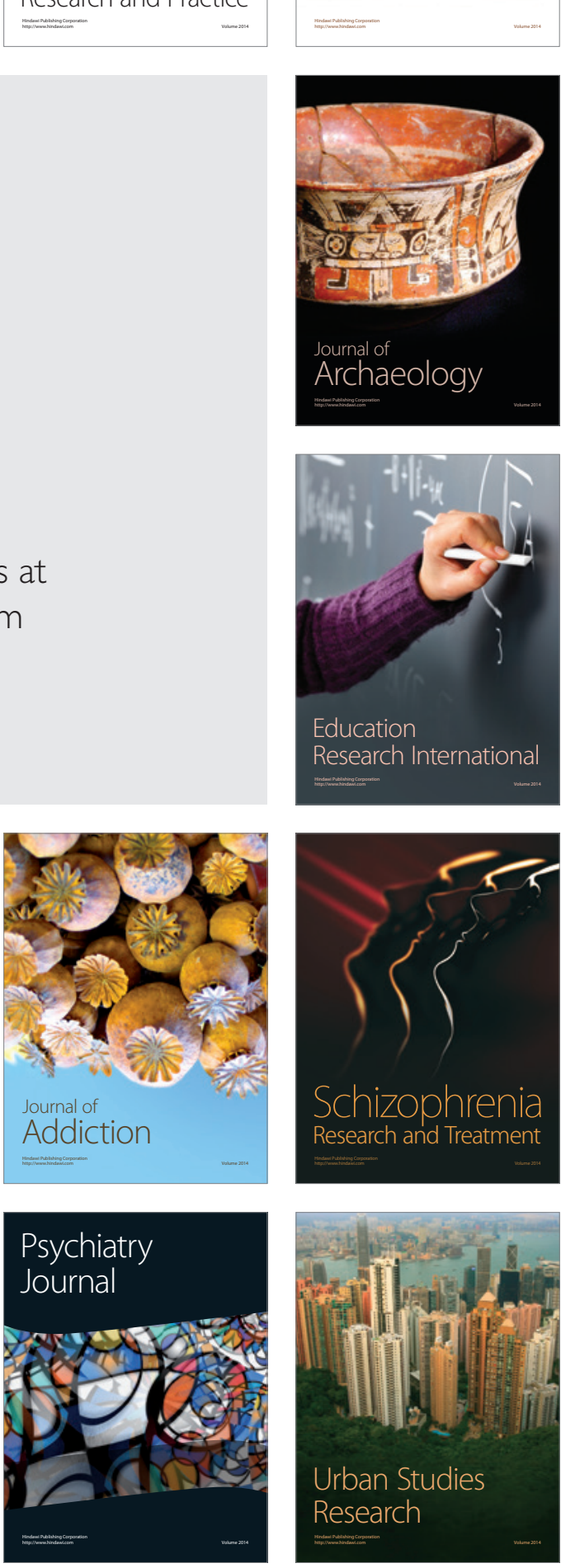